\title{
Perinatal Palliative Care Issues
}

\author{
Rita Rufo* \\ Coordinator of perinatal palliative care, Pereira Rossell Hospital Center, Uruguay
}

Submission: February 22, 2018; Published: March 21, 2018

*Corresponding author: Rita Rufo, Coordinator of Perinatal Palliative Care, Pereira Rossell Hospital Center, Montevideo, Uruguay, Email: rrufo@mednet.org.uy

\section{Abstract}

The perinatal palliative care is usually defined as an alternative when they decide to continuous. The objective is to reflect on this point. Here I develop my opinion on this, basing myself fundamentally on my experience. I believe that palliative care depends on human dignity and not on the decision of the parents to continue or not the pregnancy.

Keywords: Perinatal care; Palliative care; Perinatal palliative care

\section{Introduction}

The lethal prenatal diagnosis, in some countries, allows the couple to continue or not with pregnancy. The perinatal palliative care (PPC) is usually defined as an alternative when they decide to continuous [1]. We offer in both situations PPC because we consider the follows pillars are very important.

The First: PPC must being based in human rights so all human being have dignity and merits palliative care on the final of life.

The Second: PPC must being based in ethics decisions process. Values and bioethics principles must be considered in the analysis about the limits of therapeutics efforts. The principle of the best interest of child must be protecting to avoid unnecessary suffering.

The Thirst: PPC must being based in WHO palliative principles and definition. PPC can be provide earlier also with curative medical interventions. If fetal medicine has alternatives must be discussed with the family. If the baby's prenatal situations is so serious that a short life is expected so needs symptoms controls and family approach. The diagnosis cannot be exact and the family should contemplate a lot of uncertainty.

The Four: PPC must being a bio-psycho-social and spiritual families approach. At this point we are going to reflect.

We prefer to define: CPP is a bio-psycho-social and spiritual approach to sustain and improve the quality of life of patients and families facing the problems associated with limiting diseases and / or threatening to life that begin in the context of the perinatal stage, in a broad sense, even when illness and / or death occur later [2]. The family must be respected in its socio-economic constitution and in its religious beliefs. Respect and accompany the spiritual process, which is developed by living a pregnancy with the illness of a child, its short life, is the art of perinatal palliative care. The path should help to be blameless, not to damage selfesteem and reinforce their own coping tools. We must learn from the family the way to follow.

We must respect family beliefs. At this point we should ask ourselves: Is it possible to accompany or not accompany these families according to whether they proceed or do not proceed as we would like for us? Can we overcome prejudices to help the enormous suffering of these families? Are we really a different specialty? If everyone has dignity and rights, we should not refuse to accompany these families. We should always be willing to help them find the resources to face the deep crisis.

In my experience I have not found adverse effects of the palliative approach in this time of life. Even if the family is included early in the palliative program, for an ominous diagnosis, and the results are better than expected and can even be discharged, the families are grateful.

I tell you a case that I remember the students often. One day a couple, whose previous child died in childbirth due to polymorphs, returns to the hospital to control her new pregnancy. Pregnancy is very distressing because the diagnosis of hydrops with pulmonary hypoplasia is made and they decide to continue. They complied with all the controls and prepared for the birth of a baby with a lethal condition that may be only gave time to 
say goodbye before dying. At 35 weeks labor begins one morning while she was admitted to the hospital. In the night I receive a call from the doctor who assist the baby and says that the baby lives and asks me what to do. I answer to admit him into intensive care. A month later the child was discharged from the hospital in good health conditions.

Cases like this motivate to be prudent when explain the different possible scenarios to the family. Medicine has gray areas and prenatal diagnosis is not the exception. For this reason we must participate the family because we do not have the absolute truth. The discussion of the conduct to follow should include the beliefs and values according to the family. The quality of life should not be measured with medical eyes but with love of the family. Another situation I went on to tell you: a 25-year-old woman, in the third pregnancy is diagnosed with a fetal severe neurological malformation, in the same way as previous pregnancies, and decides to interrupt her pregnancy. They are accompanied in the three pregnancies: both at the end of the life of the fetus and in the duel. Later recovered physically and spiritually she becomes pregnant and asks for our support in spite of a normal fetus. Should we abandon them in terrible moments of their lives? We have learned to respect and to accompany the devastating suffering of these families.

\section{Conclusion}

We have learned to respect different beliefs and family constitution without judging. We believe that it is very painful what happens to them to pretend that they adapt to us. We must make every effort to understand them and help them from their own values.

Palliative care is a right of the fetus or neonate that cannot verbalize and their families without any restrictions. Palliative care depends on human dignity and not on the decision of the parents to continue or not the pregnancy.

\section{Acknowledgement}

We must thank so many families who have taught us so much and the colleagues who daily trust us.

\section{Conflict of Interest}

The author declares no conflict of interest.

\section{References}

1. Arcel AM (2016) Perinatal palliative care, the end of life when life begins, Spain.

2. Rufo R, Ettlin G, Boccarato A, Morales E, Hoppe A, et al. (2013) Perinatal palliative care: three years of experience in a motherhood. Paper presented at the XXIX Uruguayan Congress of Pediatrics 2013. LATU, Montevideo, Uruguay. In: De Pena L et al. Analysis and reflections from a bioethical perspective, in psychiatric clinical practice, in relation to a case. Psychiatrist Urug 78 (1): 31-41. 